\title{
Características físico-mecânicas de couros caprinos e ovinos no Cariri Paraibano
}

\author{
Robson José Freitas Oliveira ${ }^{1}$, Roberto Germano Costa ${ }^{2}$, Wandrick Hauss de Sousa ${ }^{3}$, \\ Ariosvaldo Nunes de Medeiros ${ }^{4}$, Egidio Luiz Furlanetto ${ }^{5}$, Delma do Socorro P. B. Aquino ${ }^{6}$
}

\author{
${ }^{1}$ Programa de Doutorado Integrado em Zootecnia, Areia - PB. \\ 2 Departamento de Agropecuária da UFPB, Bananeira - PB. \\ ${ }^{3}$ EMEPA-PB. \\ 4 UFPB - CCA, campus III, Areia - PB. \\ ${ }^{5}$ Unidade Acadêmica de Engenharia de Produção da UFCG. \\ ${ }^{6}$ Coordenação do Subprograma Setor coureiro-calçadista e afins - COMPET/CNPq.
}

RESUMO - Objetivou-se com este trabalho avaliar as características físico-mecânicas de couros de um genótipo ovino e de três genótipos caprinos. Utilizaram-se 43 peles curtidas ao cromo, provenientes de 9 ovinos Santa Inês, 12 caprinos 1/2 Anglo Nubiano, 16 1⁄2 Boer, todos mestiços com animais Sem Raça Definida (SRD), e 6 caprinos nativos denominados SRD. No período pré-experimental, todos os animais foram desmamados aos 90 dias de idade aproximadamente e criados em sistema de produção semi-intensivo utilizando pastagem cultivada. O período experimental iniciou quando os caprinos (5 meses de idade) e os ovinos (4 meses de idade), alcançaram o peso médio de 18,3 kg. Os animais foram abatidos com peso médio de $30 \mathrm{~kg}$ e idades de 180 e 270 dias, para ovinos e caprinos, respectivamente. O genótipo e a direção amostrada influenciaram o resultado do teste de resistência ao rasgamento progressivo, apesar de todos os valores terem sido inferiores aos valores de referência recomendados para um couro de boa qualidade. Nas determinações da medida de distensão e resistência da flor, não foram detectadas diferenças entre os genótipos, no entanto, no teste de resistência à tração e ao alongamento, observaram-se diferenças entre os genótipos ou a direção da amostra. Todos os resultados foram superiores aos recomendados para um produto de qualidade industrial.

Palavras-chave: curtimento, qualidade do couro, pele, resistência, curtida ao cromo

\section{Goat and sheep leather physical-mechanical characteristics in the Cariri Paraibano}

\footnotetext{
ABSTRACT - This work had as objective to evaluate the physical-mechanic characteristics of the leather from one genotype of sheep and three genotypes of goat. Forty three tanned chrome skins were used: 9 Santa Inês sheep, 12 1/2 Anglo Nubiano, 16 $1 / 2$ Boer, all crossbed with animals of non-defined breeds (NDB) and six NBD native goats. In the pre-experimental period, all animals were weaned at 90 days of age approximately and raised under semi-intensive production systems using cultivate pasture. The experimental phase began when the goat ( 5 moths of age) and sheep (4 moths of age ) reached $18.3 \mathrm{~kg}$. The animals were slaughtered with average weight of $30 \mathrm{~kg}$ with ages of 180 and 270 days, for sheep and goats, respectively. Genotype and direction factors influenced the results for the progressive tear strength, although all values have been inferior to the reference values recommended for good quality leather. In measurement of the grain distention and strength, no differences were detected among the genotypes, however, for the tensile strength and percentage elongation were observed differences among genotypes or the samples direction. All results were above to the recommended for an industrial quality product.
}

Key Words: leather quality, skin, tanning, tensile strength, wet blue

\section{Introdução}

A pele é um subproduto da produção de carne, principal objetivo na exploração caprina e ovina no Nordeste brasileiro. No entanto, este subproduto tem pouca atenção e representa de 10 a $12 \%$ do valor do animal. Com o beneficiamento, a pele se torna produto de grande expressividade econômica (Arbiza, 1986) e, segundo Jacinto (2005), se de boa qualidade, pode representar a diferença entre o lucro e o prejuízo na venda do animal.

Há muito se tem trabalhado com a premissa de que todas as peles são iguais, entretanto, de acordo com Jacinto et al. (2004), a resistência dos couros à tração e ao rasgamento é influenciada pelas características anatomoestruturais da 
pele, relacionadas à espécie, raça, idade, região e posição de retirada das amostras, o que induz a uma alta variabilidade na qualidade.

Visando melhorar geneticamente o rebanho da região e produzir animais superiores, o Governo da Paraíba importou há alguns anos animais destinados à produção de carne. No entanto, pouco se conhece sobre a pele dos animais resutantes desses cruzamentos. A pele produzida também tem apresentado baixo aproveitamento, o que, segundo Furlanetto (2003), é ocasionado principalmente pela falta de técnicas corretas para os procedimentos de abate, esfola e conservação, que geram defeitos e desvalorizam a matéria-prima.

Villarroel (2004a) verificaram que o couro de animais mestiços deslanados Santa Inês apresentou maior resistência nos testes físico-mecânicos em comparação ao de animais mestiços lanados Texel. Além disso, o uso de reprodutores lanados com ovelhas deslanadas para melhorar a produção de carne influencia negativamente a qualidade dos couros, tornando-se fator importante na determinação da qualidade do produto pela indústria coureira.

No Brasil, menos de $10 \%$ do total de peles processadas até a fase de wet blue atinge a primeira classificação. $\mathrm{O}$ direcionamento para produção de peles de qualidade é fundamental para o crescimento da caprinocultura e ovinocultura, principalmente porque esta matéria-prima promove a maior agregação de valor da cadeia produtiva (Leite \& Simplício, 2002).

O mercado de pele caprina e ovina é bastante promissor. Existe, tanto no Brasil como no exterior, uma forte demanda pelo produto, o que torna urgente a necessidade de fomentar estudos sobre as características importantes do couro destas espécies para sua utilização pela indústria transformadora, aumentando seus níveis de qualidade e produtividade.

A qualidade do couro está relacionada a características de natureza química, mecânica e estética exigidas nas indústrias curtidoras (Dal Monte, 2004). Todos os testes e as determinações físico-mecânicos devem ser executados sob padrões estabelecidos por normas técnicas que determinam a qualidade do couro. Portanto, é necessário fazer parte de um programa de qualidade da empresa curtidora (Boccone, 1978), baseado em parâmetros pré-definidos ou valores orientativos que determinam a resistência dos couros objetivando o controle de produção.

Objetivou-se com este trabalho analisar as características físico-mecânicas de couros curtidos ao cromo de quatro genótipos diferentes.

\section{Material e Métodos}

O estudo foi realizado no Centro de Ciências Agrárias, CCA, da Universidade Federal da Paraíba, UFPB. Utilizaram-se 43 peles: 9 de ovinos Santa Inês; 12 de caprinos 1/2 Anglo-Nubiano; 16 1⁄2 Boer; e 6 de caprinos nativos SRD.

As peles dos ovinos foram provenientes de animais da Estação Experimental de Pendência - EMEPA, localizada em Soledade, PB, região do Curimataú Ocidental. As peles dos caprinos foram obtidas em propriedades particulares localizadas no Cariri Paraibano.

Todos os animais, desmamados em idade de 90 a 112 dias, foram criados sob regime semi-intensivo em pastagens nativas de caatinga utilizando-se manejo tradicional desenvolvido na região.

Os animais, machos inteiros, com peso médio de $18,3 \mathrm{~kg}$ entraram em fase experimental aproximadamente aos 5 meses (caprinos) e aos 4 meses de idade (ovinos). Foram submetidos ao controle sanitário e alojados em quatro baias coletivas, cobertas, com piso de chão batido, onde foram mantidos por 14 dias para adaptação às instalações e ao manejo. A dieta foi composta de silagem de milho e concentrado à base de milho, soja, trigo, melaço e minerais, com relação volumoso:concentrado 40:60, de acordo as exigências do NRC (1985)

O abate foi realizado à medida que os animais atingiram o peso médio de $30 \mathrm{~kg}$, ou seja, em idade de 180 a 270 dias de idade, por meio de atordoamento por concussão cerebral, suspensão dos animais pelas patas traseiras, sangria pela veia jugular e esfola manual. As peles foram salgadas e armazenadas conforme metodologia descrita por Silva Sobrinho \& Jacinto (1992) e, após 40 dias, foram encaminhadas ao Centro de Tecnologia do Couro e do Calçado Albano Franco/CTCC/SENAI, onde foram submetidas aos processos de curtimento e recurtimento, conforme o padrão do CTCC, e aos testes físico-mecânicos.

O curtimento foi realizado segundo metodologia de Badische Anilin und Soda-Fabriken - BASF (1976), seguindo as etapas de remolho, caleiro, desencalagem, purga, desengraxe, píquel, curtimento, basificação, neutralização, recurtimento, secagem e amaciamento.

Depois de curtidos, os couros foram climatizados a $23 \pm 2{ }^{\circ} \mathrm{C}$ e umidade relativa de $50 \pm 5 \%$ durante 48 horas antes dos testes físicos-mecânicos, segundo norma NBR 10455 (ABNT, 1988). As medidas da espessura dos couros, necessárias aos cálculos de resistência à tração e ao rasgamento, foram aferidas em espessímetro, conforme norma NBR 11052 (ABNT, 1997). 
Os corpos-de-prova para os ensaios de resistência à tração e ao rasgamento progressivo foram retirados na prensa hidráulica, modelo balancim, por meio de navalhas com dimensões descritas nas normas NBR 11035 (ABNT, 1990).

Os testes de resistência à tração e ao alongamento e a determinação da força de rasgamento progressivo foram realizados em equipamento dinamômetro, segundo normas NBR 11041 (ABNT, 1997) e NBR 11055 (ABNT, 1997), respectivamente.

Para determinação da ruptura e da distensão da flor do couro pelo lastômetro, foram retirados três corpos-deprova nos formatos e tamanhos estabelecidos na norma NBR 11669 (ABNT, 1991).

Utilizou-se delineamento inteiramente casualizado para medida da distensão e resistência da flor e um arranjo fatorial $4 \times 2$ para resistência ao rasgamento progressivo, à tração e ao alongamento. Os dados foram submetidos à análise de variância e as médias dos testes físicos-mecânicos foram comparadas pelo teste Tukey a 5\% de probabilidade, pelo procedimento GLM do SAS (1999).

\section{Resultados e Discussão}

A espessura do couro não diferiu significativamente $(\mathrm{P}>0,05)$ entre os genótipos (Tabela 1). Não houve diferença significativa $(\mathrm{P}>0,05)$ entre os genótipos quanto à força aplicada; observou-se significância apenas para a direção amostrada. Os resultados da resistência diferiram $(\mathrm{P}<0,05)$ tanto entre genótipos quanto entre direções.

Verificou-se resultado significativo $(\mathrm{P}<0,05)$ entre as direções longitudinal e transversal; o resultado obtido para a direção transversal foi superior ao da longitudinal, o que está de acordo com resultados de outros estudos histológicos da pele (Junqueira \& Carneiro, 1995; Jacinto, 2004), e está relacionado à disposição longitudinal das fibras de colágeno, que exercem influência no sentido da resistência ao rasgamento. No entanto, este resultado contradiz os encontrados por Villarroel (2004b) e Dal Monte (2004), que não detectaram diferenças significativas entre as duas direções amostradas.

Apesar da influência do genótipo sobre a resistência, o valor referência mínimo estabelecido pelo laboratório de controle de qualidade do SENAI-CTCC (Centro de tecnologia do couro e calçado Albano Franco) para o teste de qualidade da estrutura fibrosa por meio da resistência ao rasgamento progressivo é de $80 \mathrm{kgf} / \mathrm{cm}$, de modo que os couros de todas as raças avaliadas estão abaixo desses parâmetros de referência especificados.

Vários trabalhos (Costa, 1998a; Dal Monte, 2004) apresentam resultados de couros caprinos e ovinos, para a
Tabela 1 - Resistência ao rasgamento progressivo de couros de animais de diferentes genótipos

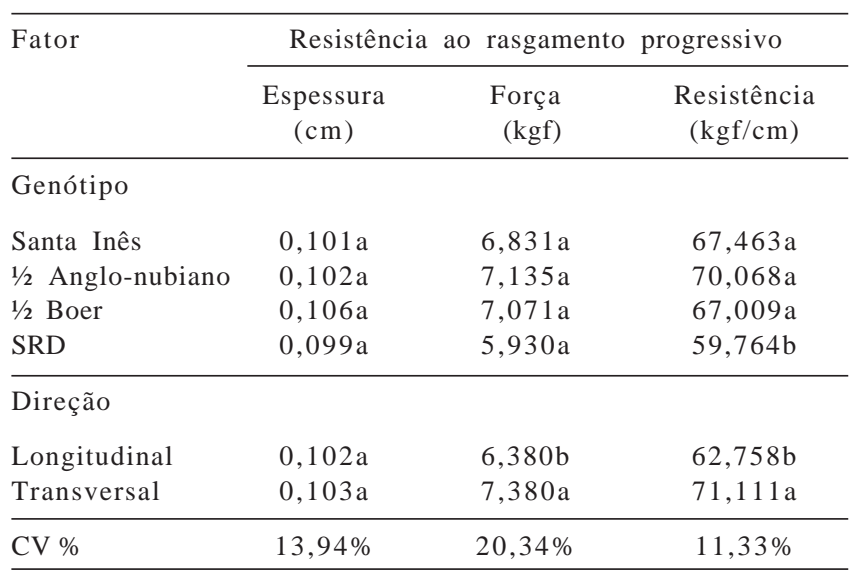

Médias com letras diferentes na coluna diferem $(P<0,05)$ pelo teste Tukey.

variável resistência ao rasgamento progressivo, superiores aos sugeridos pelo laboratório de controle de qualidade do SENAI - CTCC. Portanto, é necessário esclarecer os defeitos que podem alterar os resultados dos testes físico-mecânicos: estado de conservação das peles antes do curtimento; falhas no controle durante o processamento da pele; produtos químicos mal estocados; falta de climatização adequada da amostra antes dos testes; defeitos na amostragem; ou mesmo falhas no manuseio e na leitura dos equipamentos. Os baixos valores encontrados podem ser atribuídos a alguns destes fatores, uma vez que, segundo Jardim (1984), a pele caprina é um produto de boa qualidade, com alta resistência e elasticidade.

Os resultados de resistência à tração e ao alongamento diferiram significativamente entre os genótipo e as direções estudadas (Tabela 2).

A característica espessura não diferiu $(\mathrm{P}>0,05)$ entre os genótipo e as direções testadas. Para as características força (kgf) e tensão $\left(\mathrm{kgf} / \mathrm{cm}^{2}\right)$, foram encontrados resultados significativos $(\mathrm{P}<0,05)$. Assim, a espessura da pele não influenciou a quantidade de força aplicada nem a tensão resultante, que caracteriza a resistência do couro. Como não houve variação na espessura do couro, quanto maior a força aplicada, maior a resistência ou tensão, portanto, o resultado de tensão está relacionado ao genótipo ou à direção amostrada, de modo que os genótipos 1/2 Anglo e Santa Inês foram superiores ao $1 \frac{1}{2}$ Boer e SRD e a direção longitudinal foi superior à transversal.

Os valores obtidos para a direção da amostra condizem com o esperado, pois são influenciados pela disposição longitudinal das fibras de colágeno, inverso ao resultado de rasgamento progressivo. Esse resultado confirma os encontrados por Dal Monte (2004), que detectou diferença signi- 
Tabela 2 - Resistência à tração e ao alongamento de couros de diferentes genótipos

\begin{tabular}{lcccc}
\hline Fator & \multicolumn{5}{c}{ Resistência à tração e ao alongamento } \\
\cline { 2 - 5 } & $\begin{array}{c}\text { Espessura } \\
(\mathrm{cm})\end{array}$ & $\begin{array}{c}\text { Força } \\
(\mathrm{kgf})\end{array}$ & $\begin{array}{c}\text { Tensão } \\
\left(\mathrm{kgf} / \mathrm{cm}^{2}\right)\end{array}$ & $\begin{array}{c}\text { Alongamento } \\
(\%)\end{array}$ \\
\hline Genótipo & & & & \\
Santa Inês & $0,100 \mathrm{a}$ & $25,91 \mathrm{a}$ & $260,17 \mathrm{a}$ & $52,389 \mathrm{~b}$ \\
1/2 Anglo-nubiano & $0,102 \mathrm{a}$ & $26,75 \mathrm{a}$ & $263,45 \mathrm{a}$ & $57,125 \mathrm{a}$ \\
1/2 Boer & $0,104 \mathrm{a}$ & $23,23 \mathrm{ab}$ & $223,46 \mathrm{~b}$ & $52,875 \mathrm{~b}$ \\
SRD & $0,098 \mathrm{a}$ & $21,70 \mathrm{~b}$ & $219,42 \mathrm{~b}$ & $54,250 \mathrm{a}$ \\
\hline Direção & & & & \\
Longitudinal & $0,102 \mathrm{a}$ & $27,48 \mathrm{a}$ & $269,616 \mathrm{a}$ & $49,186 \mathrm{~b}$ \\
Transversal & $0,102 \mathrm{a}$ & $21,64 \mathrm{~b}$ & $213,859 \mathrm{~b}$ & $59,116 \mathrm{a}$ \\
\hline CV \% & $13,43 \%$ & $19,74 \%$ & $14,19 \%$ & $10,63 \%$ \\
\hline
\end{tabular}

Médias com letras diferentes na coluna diferem $(P<0,05)$ pelo teste Tukey.

ficativa entre as direções amostradas, com superioridade da direção longitudinal sobre a transversal. Diferem, no entanto, dos relatados por Villarroel (2004b).

Todos os resultados foram superiores ao mínimo de $200 \mathrm{kgf} / \mathrm{m}^{2}$ preconizado pelo Laboratório de Controle de Qualidade do SENAI - CTCC para um couro de qualidade industrial e confirmam os resultados obtidos por Dal Monte (2004) e Villarroel(2004b).

O percentual de alongamento também sofreu influência significativa $(\mathrm{P}<0,05)$ do genótipo e da direção, mas não esteve relacionado à força ou à tensão. Para esta característica, os couros dos genótipos 1/2 Anglo e SRD apresentaram valores superiores aos de animais $1 / 2$ Boer e Santa Inês; os resultados obtidos na direção transversal foram melhores que os determinados na direção longitudinal. Para esta característica, todos os genótipos e as direções atenderam aos parâmetros preconizados de 40 a $80 \%$ pelo Laboratório de Controle de Qualidade do SENAI - CTCC.

Pelo teste de ruptura da esfera, executado pelo aparelho lastômetro, o corpo-de-prova amostrado é de forma circular e a posição de retirada das amostras não é considerada (Tabela 3). Assim, as posições de direção longitudinal e transversal não são referenciadas.

Não foram detectadas diferenças significativas $(\mathrm{P}>0,05)$ para espessura ou distensão da flor entre os genótipos avaliados. Costa et al. (1998b), em pesquisa com animais de diferentes idades, observaram diferença significativa na espessura dos couros e comprovaram variação crescente à medida que avança a idade. Esse fator pode justificar a nãosignificância na espessura dos couros entre as espécies ovino e caprinos, uma vez que os ovinos foram abatidos mais jovens que os caprinos.

Ressalta-se que, para todas as raças, os valores de distensão foram superiores ao de 7,00 mm preconizado
Tabela 3 - Medida da distensão da flor em relação ao genótipo Fator Medida da distensão e resistência da flor

\begin{tabular}{lcc}
\cline { 2 - 3 } & Espessura $(\mathrm{cm})$ & Distensão $(\mathrm{mm})$ \\
\hline Genótipo & & \\
Santa Inês & $0,982 \mathrm{a}$ & $8,358 \mathrm{a}$ \\
$1 / 2$ Anglo-nubiano & $1,009 \mathrm{a}$ & $8,124 \mathrm{a}$ \\
$1 / 2$ Boer & $1,029 \mathrm{a}$ & $7,976 \mathrm{a}$ \\
SRD & $0,957 \mathrm{a}$ & $8,193 \mathrm{a}$ \\
\hline CV $\%$ & $13,27 \%$ & $8,48 \%$ \\
\hline
\end{tabular}

Médias com letras diferentes na coluna diferem $(P<0,05)$ pelo teste Tukey.

pelo Laboratório de Controle de Qualidade do SENAI CTCC como mínimo para um couro de qualidade industrial.

\section{Conclusões}

Os resultados de resistência ao rasgamento progressivo do couro de todos os genótipos foram inferiores ao valor mínimo orientativo recomendado. Para os demais testes aplicados (resistência a tração e ao alongamento e medida da distensão da flor), as características físico-mecânicas foram compatíveis aos padrões estabelecidos pela indústria coureira para um couro de boa qualidade.

\section{Literatura Citada}

ARBIZA, S.I.A. Products caprinos. In:_ Producción de caprinos. México: AGT Editora, 1986. p.105-181.

ASSOCIAÇÃO BRASILEIRA DE NORMAS TÉCNICAS - ABNT. Climatização de materiais usados na fabricação de calçados e correlatos, NBR 10455. Rio de Janeiro, 1988. 5p. Corte de corpos-de-prova em couro, NBR 11035

Rio de Janeiro, 1990. 1p.

Couros: determinação da ruptura e da distensão da flor - Lastômetro, NBR 11669. Rio de Janeiro, 1991. 4p.

. Determinação da espessura. NBR 11052. Rio de Janeiro: ABNT, 1997

BADISCHE ANILIN UND SODA-FABRIKEN - BASF. Pieles de animales pequeños: curtición, recurtición, tintura, engrase y acabado. Ludwigshafen: 1976. 41p.

BOCCONE, R.I; FONTANA, J.A; KAMP, G. Distribution of mechanical prperties in wool-on sheepskins. Journal of the Society of Leather Trades Chemists, v.62, p.128-132, 1978.

COSTA, R.G.; PIMENTA FILHO, E.C.; RIBEIRO, M.N. et al. Qualidade do couro de caprinos submetidos a diferentes níveis de substituição do leite por soro de queijo até a desmama. Revista Brasileira de Zootecnia v.27, n.2, p.359-361, 1998a.

COSTA, R.G.; PIMENTA FILHO, E.C; SILVA, A.F.R. et al. Efeito da idade do animal na qualidade do couro de caprinos criados em regime semi-extensivo. Revista Brasileira de Zootecnia v.27, n.2, p.355-358, 1998b.

DAL MONTE, M.A.B.L; COSTA, R.G.; JACINTO, M.A.C. et al. Caracterísitcas físico-mecânicas e químicas do couro de caprinos abatidos em idades diferenciadas. Revista Brasileira de Zootecnia, v.33, n.5, p.1285-1291, 2004.

FURLANETTO, E.L. Estudo da cadeia produtiva do couro no estado da Paraíba: diagnóstico. In: ENCONTRO PARA ESTRUTURAÇÃO 
DA CADEIA PRODUTIVA DA CAPRINO-OVINOCULTURA PARAIBANA, 2003, Campina Grande. Palestras... Campina Grande: FINEP/FAPESP, 2003.

JACINTO, M.A.C.; COSTA, R.G.; LEITE, E.R. Produção de peles e couros caprinos e ovinos. In: REUNIÃO ANUAL DA SOCIEDADE BRASILEIRA DE ZOOTECNIA, 42., 2005. Goiânia. Anais... Goiânia: Sociedade Brasileira de Zootecnia, 2005. p.157-165.

JACINTO, M.A.C.; SILVA SOBRINHO, A.G.; COSTA, R.G. Características anátomo-estruturais da pele de ovinos (Ovis aries L.) lanados e deslanados, relacionadas com o aspecto físicomecânico do couro. Revista Brasileira de Zootecnia, v.33, n.4, p.1001-1008, 2004.

JARDIM, W.R. Criação de caprinos. 11.ed. São Paulo: Nobel, 1984. 353p.

JUNQUEIRA, L.C.; CARNEIRO, J. Histologia básica. Rio de Janeiro: Guanabara Koogan, 1995. p.271-280.
LEITE, E.R.; SIMPLÍCIO, A.A. Produção mercado das peles caprina e ovina. Sobral: Embrapa Caprinos, 2002. 27p.

NATIONAL RESEARCH COUNCIL - NRC. Nutrient requirements of sheep. 6.rev.ed. Washington, D.C.: 1985. $99 \mathrm{p}$.

STATISTICAL ANALYSIS SYSTEM - SAS. User's guide: statistics. Cary, 1999. (CD-ROM).

SILVA SOBRINHO, A.G.; JACINTO, M.A.C. Peles ovinas. 1.ed. Jaboticabal: FUNEP, 1992. 33p.

VILLARROEL, A.B.S; COSTA, R.G.; OLIVEIRA, S.M.P. Características físico-mecânicas do couro de ovinos mestiços Santa Inês e Texel. Revista Brasileira de Zootecnia v.33, n.6, p.2373-2377, 2004a (supl. 3).

VILLARROEL, A.B.S.; COSTA, R.G.; OLIVEIRA, S.M.P. Características físico-mecânicas do couro de caprinos mestiços Boer e Anglo Nubianos. Revista Brasileira de Zootecnia v.33, n.6, p.2369-2372, 2004b (supl. 3). 